Supporting Information for:

\title{
Thiopeptide defense by an ant's bacterial symbiont
}

Preston T. Chang, ${ }^{\dagger}$ Krithika Rao, ${ }^{\dagger}$ Lauren O. Longo, Elisabeth S. Lawton, Georgia Scherer, and Ethan B. Van Arnam*

Keck Science Department of Claremont McKenna, Pitzer, and Scripps Colleges, Claremont, CA 91711, United States

${ }^{\dagger}$ these authors contributed equally

*to whom correspondence should be addressed: evanarnam@kecksci.claremont.edu

Table S1. Pseudonocardia isolates used in this study.

\begin{tabular}{|c|c|c|c|c|c|}
\hline Abbreviation & Strain ID & Collection Location & $\begin{array}{l}\text { Collection } \\
\text { Date }\end{array}$ & $\begin{array}{l}\text { Host Ant } \\
\text { Species }\end{array}$ & $\begin{array}{l}\text { 16S rRNA } \\
\text { GenBank } \\
\text { accession }\end{array}$ \\
\hline 17SE-1 & EV170527-01 & Centereach, New York, USA & $05-2017$ & $\begin{array}{l}\text { Trachymyrmex } \\
\text { septentrionalis }\end{array}$ & MN893873 \\
\hline 17SE-3 & EV170527-03 & Centereach, New York, USA & $05-2017$ & $\begin{array}{l}\text { Trachymyrmex } \\
\text { septentrionalis }\end{array}$ & MN893874 \\
\hline 17SE-4 & EV170527-04 & Centereach, New York, USA & $05-2017$ & $\begin{array}{l}\text { Trachymyrmex } \\
\text { septentrionalis }\end{array}$ & MN893875 \\
\hline 17SE-6 & EV170527-06 & Centereach, New York, USA & $05-2017$ & $\begin{array}{l}\text { Trachymyrmex } \\
\text { septentrionalis }\end{array}$ & MN893876 \\
\hline 17SE-7 & EV170527-07 & Centereach, New York, USA & $05-2017$ & $\begin{array}{l}\text { Trachymyrmex } \\
\text { septentrionalis }\end{array}$ & MN893877 \\
\hline 17SE-8 & EV170527-08 & Centereach, New York, USA & $05-2017$ & $\begin{array}{l}\text { Trachymyrmex } \\
\text { septentrionalis }\end{array}$ & MN893878 \\
\hline 17SE-9 & EV170527-09 & Centereach, New York, USA & $05-2017$ & $\begin{array}{l}\text { Trachymyrmex } \\
\text { septentrionalis }\end{array}$ & MN893879 \\
\hline 17SE-10 & EV170527-10 & Centereach, New York, USA & $05-2017$ & $\begin{array}{l}\text { Trachymyrmex } \\
\text { septentrionalis }\end{array}$ & MN893880 \\
\hline 17SE-11 & EV170527-11 & Centereach, New York, USA & $05-2017$ & $\begin{array}{l}\text { Trachymyrmex } \\
\text { septentrionalis }\end{array}$ & MN893881 \\
\hline $17 S M-1$ & EV170708-01 & $\begin{array}{c}\text { Tellbrook Park, Las Cruces, New } \\
\text { Mexico, USA }\end{array}$ & $07-2017$ & $\begin{array}{l}\text { Trachymyrmex } \\
\text { smithi }\end{array}$ & \\
\hline $18 A Z-4$ & KR180730-01 & $\begin{array}{c}\text { Southwestern Research Station, Portal, } \\
\text { Arizona, USA }\end{array}$ & $07-2018$ & $\begin{array}{l}\text { Trachymyrmex } \\
\text { arizonensis }\end{array}$ & \\
\hline 18PO-3 & KR180731-01 & $\begin{array}{c}\text { Southwestern Research Station, Portal, } \\
\text { Arizona, USA }\end{array}$ & 07-2018 & $\begin{array}{l}\text { Trachymyrmex } \\
\text { pomonae }\end{array}$ & \\
\hline PLR1* & EC080529-01 & Panama Canal Zone, Panama & $05-2008$ & $\begin{array}{c}\text { Apterostigma } \\
\text { dentigerum }\end{array}$ & \\
\hline
\end{tabular}

${ }^{\star}$ First reported in: Caldera, E. J.; Currie, C. R. The American Naturalist 2012, 180 (5), 604-617 
Figure S1. (A) HR-ESI-MS spectrum of GE37468 from Streptomyces ATCC 55365. (B) HRESI-MS spectrum of GE37468 from Pseudonocardia 17SE-9. (C) LCMS extracted ion chromatograms of the GE37468 $[\mathrm{M}+\mathrm{H}]^{+}$ion $(\mathrm{m} / \mathrm{z}=1309.26)$ of $\mathrm{GE37468}$ purified from Streptomyces ATCC 55365 (blue) and from Pseudonocardia 17SE-9 (red).
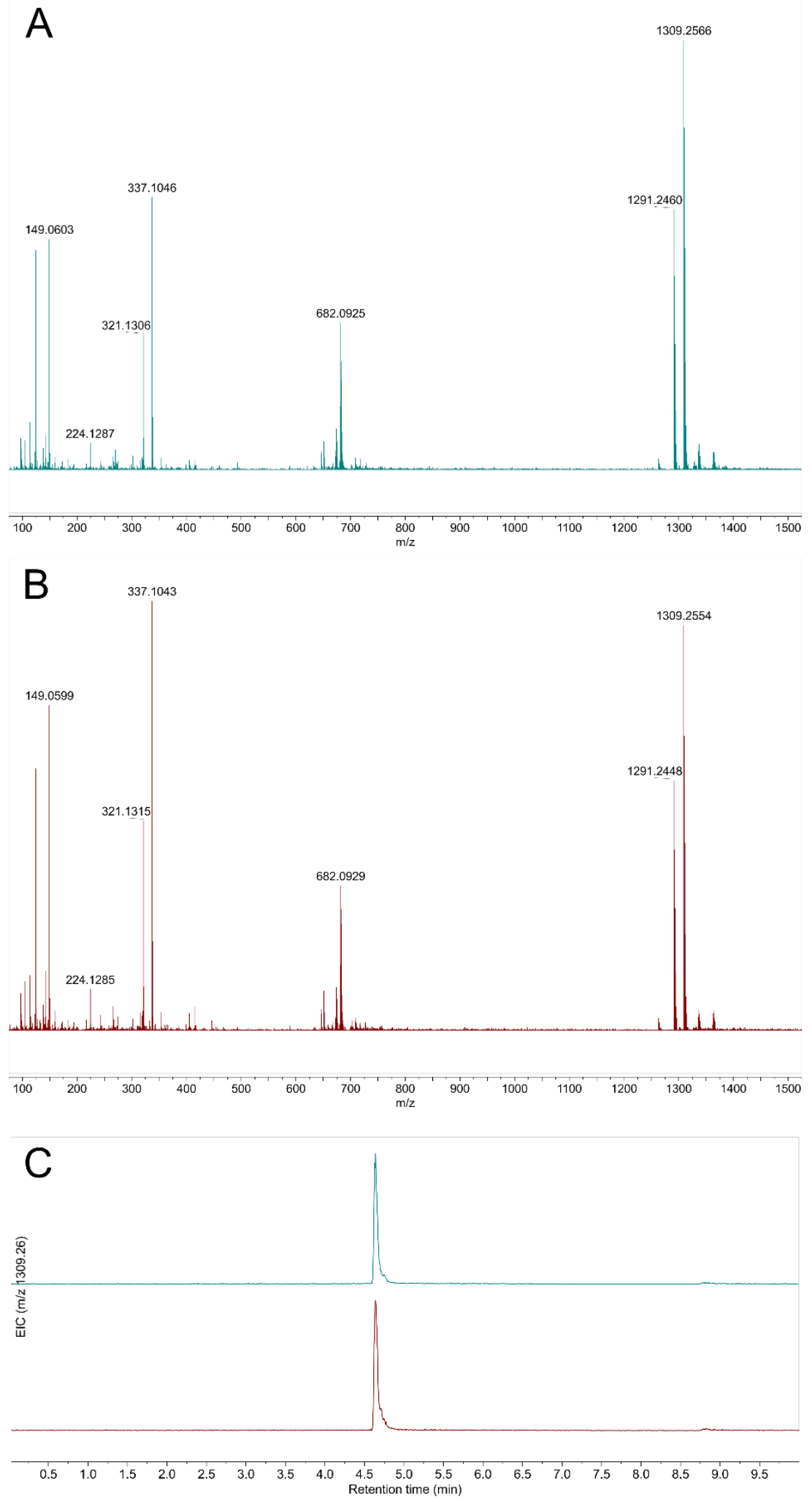
Figure S2. Representative Escovopsis inhibition assay plates. (A) Escovopsis paired with Pseudonocardia 17SE-9. (B) Escovopsis-only control.
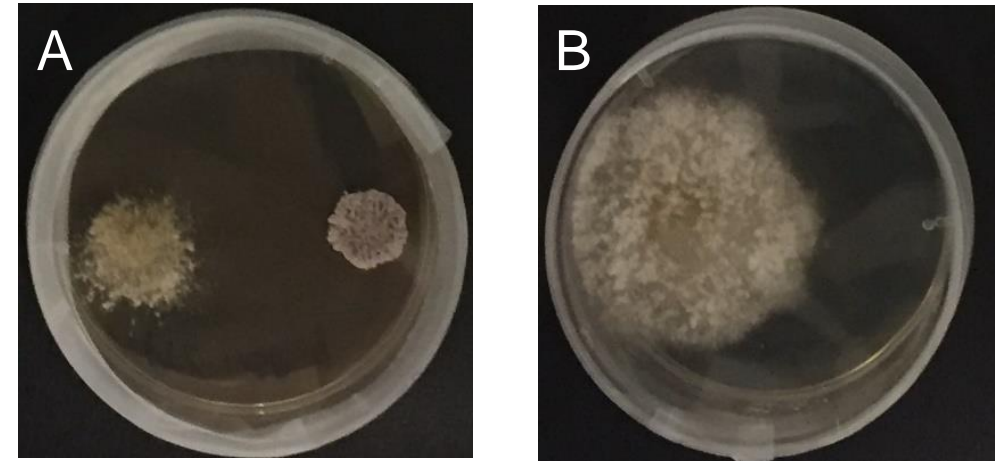

Figure S3. LCMS extracted ion chromatograms of the GE37468 [M-OH]+ ion $(\mathrm{m} / \mathrm{z}=1291.25)$ from semi-pure extracts of $T$. septentrionalis-derived Pseudonocardia cultures.

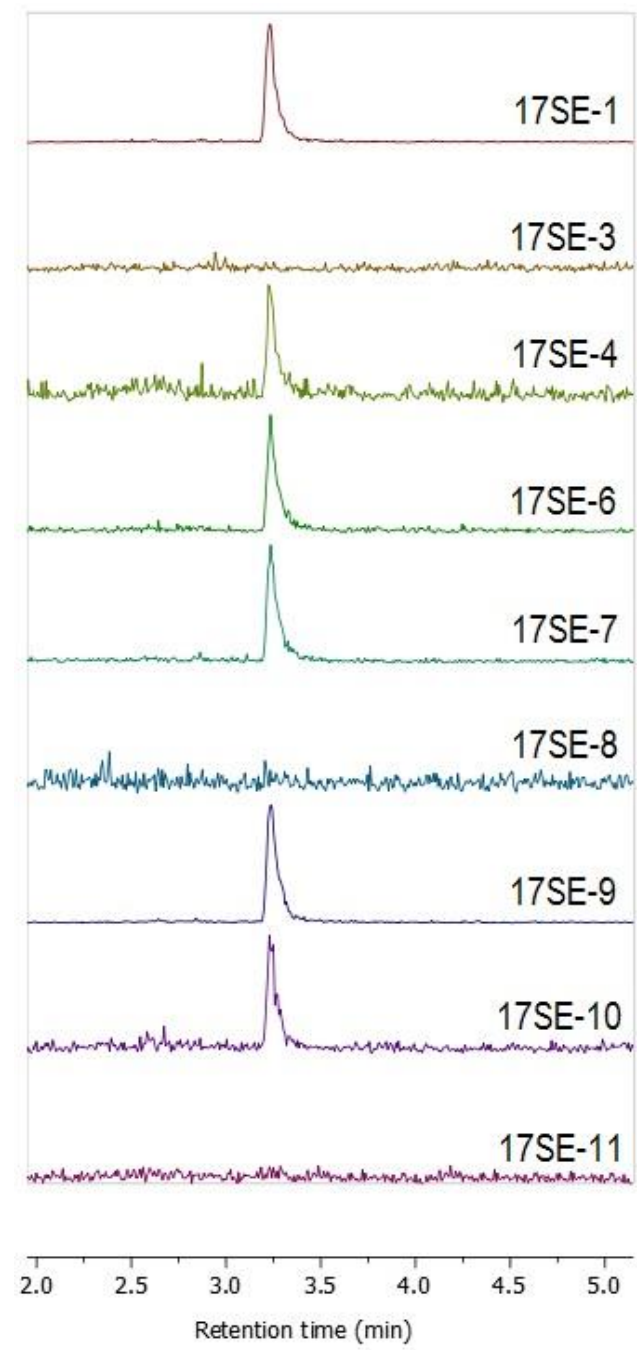


Table S2. Genes of the GE37468 biosynthetic gene cluster with protein sequence identities between Pseudonocardia 17SE-9 and Streptomyces ATCC 55365. Protein function assignments are from Young and Walsh. ${ }^{1}$

\begin{tabular}{|c|c|c|}
\hline Gene & Protein Function & $\begin{array}{l}\text { Pseudonocardia-Streptomyces } \\
\text { Protein Sequence Identity (\%) }\end{array}$ \\
\hline get $A$ & Precursor peptide & 98 \\
\hline get $B$ & Efflux/host resistance & 84 \\
\hline getC & Efflux/host resistance & 89 \\
\hline get $D$ & Dehydratase & 82 \\
\hline getE & Dehydratase & 78 \\
\hline getF & Putative aza-Diels-Alderase & 79 \\
\hline getG & Dehydrogenase & 83 \\
\hline getH & Unknown & 80 \\
\hline getl & Cyclodehydratase & 86 \\
\hline getJ & Other post-translational modification & 86 \\
\hline getK & Dehydrogenase & 75 \\
\hline getL & Transcription Regulator & 77 \\
\hline getM & Other post-translational modification & 84 \\
\hline
\end{tabular}


Table S3. Putative GE37468 biosynthetic gene clusters and source strain information.

\begin{tabular}{|c|c|c|c|c|}
\hline Strain & Isolation source & Isolation location & $\begin{array}{c}\text { GenBank } \\
\text { accession number }\end{array}$ & Reference \\
\hline $\begin{array}{l}\text { Pseudonocardia } \\
\text { 17SE-9 }\end{array}$ & $\begin{array}{c}\text { T. septentrionalis } \\
\text { ant }\end{array}$ & Centereach, New York, USA & VRMC00000000 & This study \\
\hline $\begin{array}{l}\text { Streptomyces } \\
\text { ATCC } 55365\end{array}$ & Soil & Lamole, Italy & JN052143 & (2) \\
\hline $\begin{array}{l}\text { Streptomyces } \\
\text { bungoensis }\end{array}$ & Soil & Yabakei, Ohita, Japan & KQ948851 & (3) \\
\hline $\begin{array}{l}\text { Streptomyces } \\
\text { griseocarneus }\end{array}$ & Soil & Namihana, Tiba, Japan & PENC01000003 & (4) \\
\hline $\begin{array}{l}\text { Streptomyces } \\
\text { griseochromogenes }\end{array}$ & Soil & Gazaki, Wakayama, Japan & СР016279 & (5) \\
\hline $\begin{array}{l}\text { Streptomyces } \\
\text { NL15-2K }\end{array}$ & Soil & $\begin{array}{c}\text { Vancouver, British Columbia, } \\
\text { Canada }\end{array}$ & BHXA01000135 & (6) \\
\hline
\end{tabular}

Figure S4. Putative GE37468 biosynthetic gene clusters. Annotated genes with unknown function are shown in white.
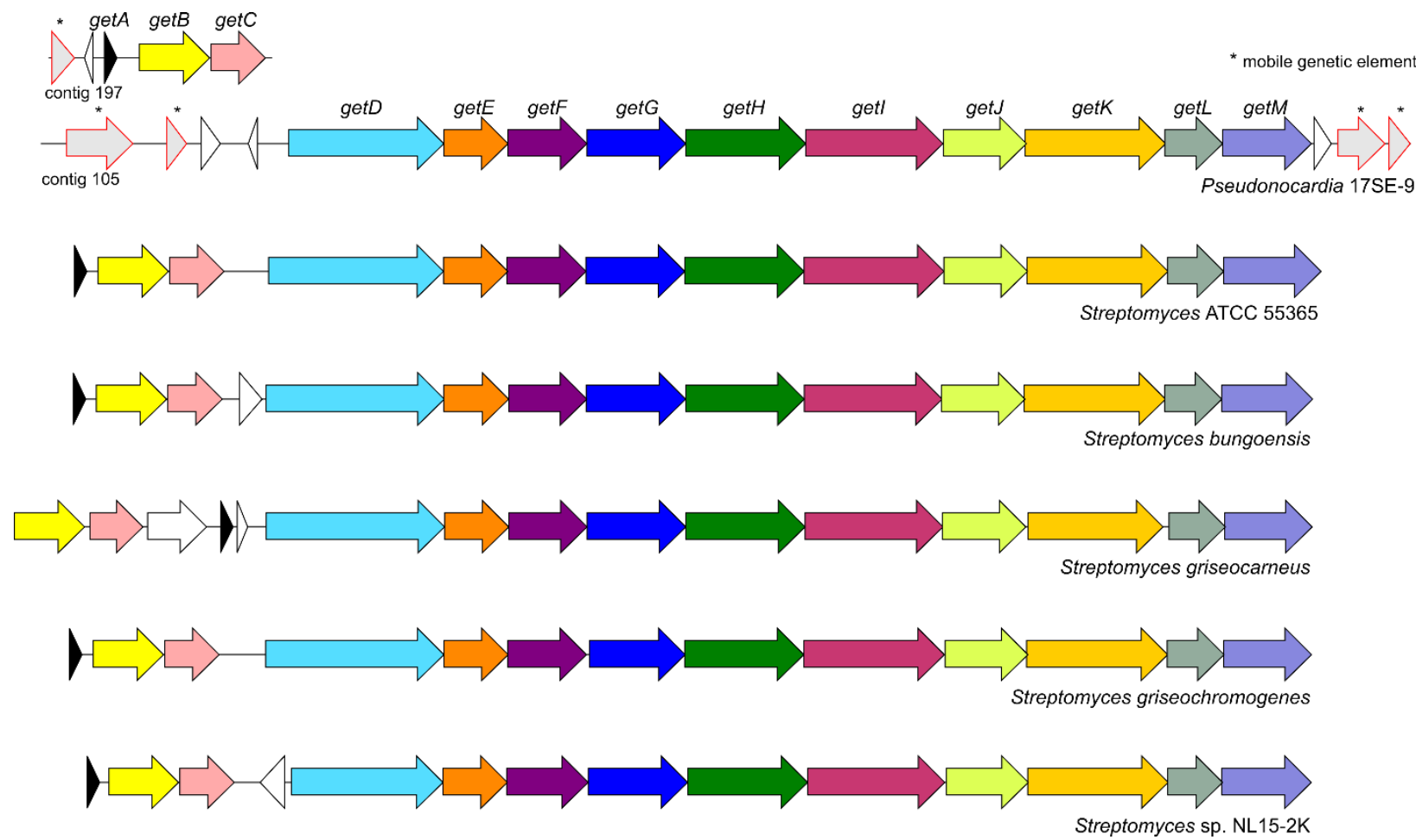
Figure S5. Phylogeny of the top 25 BLAST hits for putative aza-Diels-Alderase GetF.

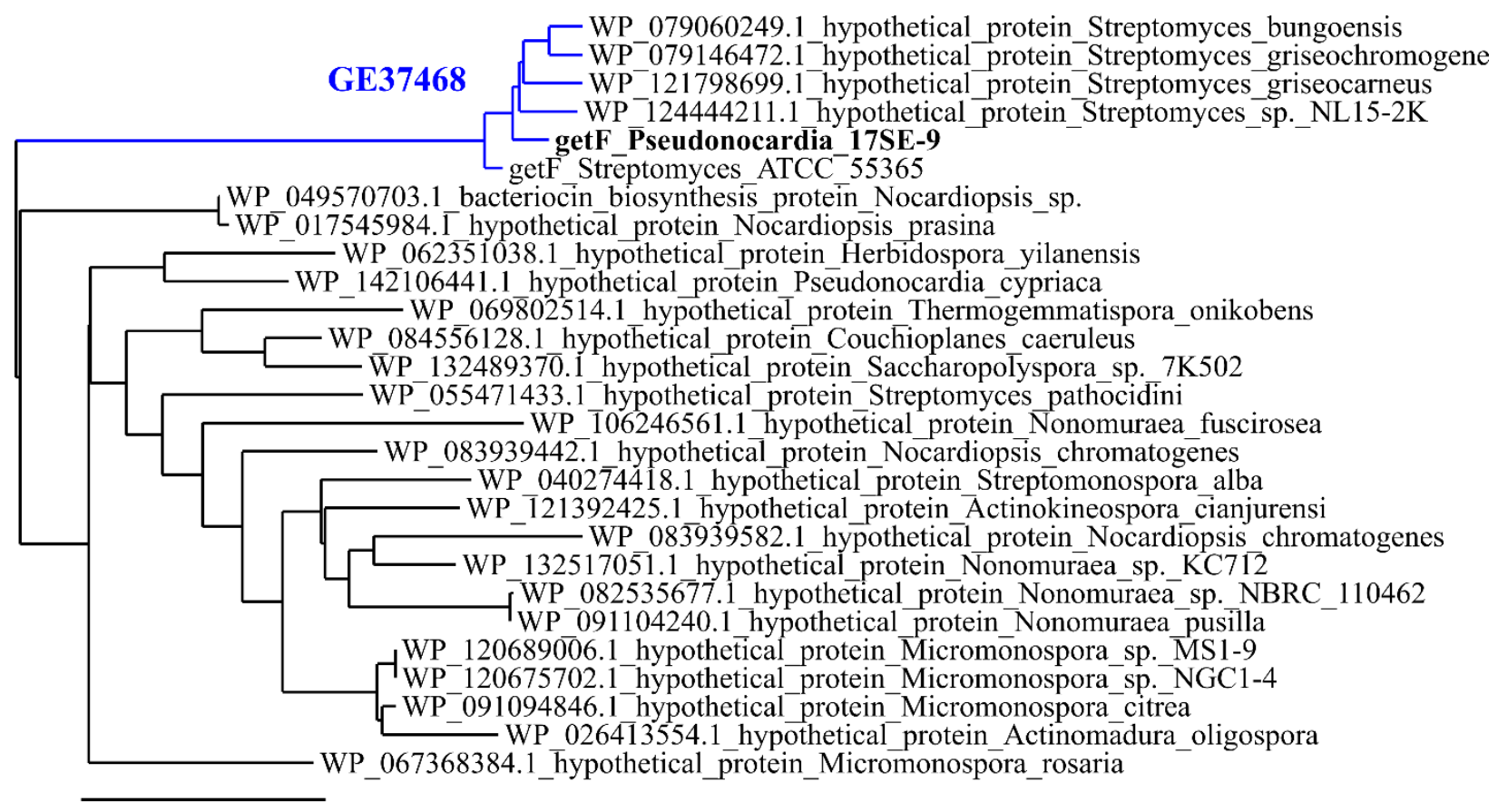

0.5

\section{Supporting Information References}

(1) Young, T. S.; Walsh, C. T. Identification of the Thiazolyl Peptide GE37468 Gene Cluster from Streptomyces ATCC 55365 and Heterologous Expression in Streptomyces Lividans. Proc Natl Acad Sci U S A 2011, 108 (32), 13053-13058. https://doi.org/10.1073/pnas.1110435108.

(2) Stella, S.; Montanini, N.; Monnier, F. L.; Ferrari, P.; Colombo, L.; Landini, P.; Ciciliato, I.; Goldstein, B. P.; Selva, E.; Denaro, M. Antibiotic GE37468 A: A New Inhibitor of Bacterial Protein Synthesis. I. Isolation and Characterization. The Journal of Antibiotics 1995, 48 (8), 780-786. https://doi.org/10.7164/antibiotics.48.780.

(3) Eguchi, T.; Takada, N.; Nakamura, S.; Tanaka, T.; Makino, T.; Oshima, Y. Streptomyces Bungoensis Sp. Nov. International Journal of Systematic Bacteriology 1993, 43 (4), 794798. https://doi.org/10.1099/00207713-43-4-794.

(4) Benedict, R. G.; Lindenfelser, L. A.; Stodola, F. H.; Traufler, D. H. Studies on Streptomyces Griseocarneus and the Production of Hydroxystreptomycin. Journal of Bacteriology 1951, 62 (4), 487-497.

(5) Fukunaga, K.; Misato, T.; Ishii, I.; Asakawa, M. Blasticidin, A New Anti-Phytopathogenic Fungal Substance. Part I. Bulletin of the Agricultural Chemical Society of Japan 1955, 19 (3), 181-188. https://doi.org/10.1080/03758397.1955.10857286.

(6) Nishimura, M.; Kawakami, S.; Otsuka, H. Draft Genome Sequence of Streptomyces Sp. Strain NL15-2K, a Degrader of Lignin-Derived Aromatic Compounds, Isolated from Forest Soil. Microbiol Resour Announc 2019, 8 (10), e01456-18. https://doi.org/10.1128/MRA.01456-18. 